\title{
Severe acute respiratory syndrome and Toronto
}

\section{Regan}

\section{Early detection and isolation of suspected cases is the key}

"I hold my breath in elevators even empty ones". ${ }^{1}$ This was the view of one Toronto resident I read in a local newspaper in late April this year. I had just joined, as an observer, the Federal Emergency Operations Centre that had been activated by Health Canada to coordinate efforts to contain and control the spread of SARS. However, my perception was that Canadians in general appear to have responded calmly and positively to the appearance of severe acute respiratory syndrome (SARS) and to the open and frank communication from territorial, provincial, and federal authorities about the infection and the measures they could take to protect themselves. Some political accusations and recriminations have followed over the handling of the SARS outbreak, ${ }^{23}$ but the overall impression that I was left with was of a calm and well informed public who had confidence in the measures being taken by health officials and politicians under extreme pressure to manage a new infection that is yet to be fully understood.

The emergence of SARS and its health, social, and economic impacts has been the subject of intense international discussion and collaboration. The facts concerning the origin of SARS associated coronavirus are becoming clearer and the clinical and epidemiological features are being pieced together to give an increasingly coherent perspective on this new infection. ${ }^{4}$ Optimal public health management has yet to be determined. This ultimately may have as much to do with local custom and practices concerning the role of the state and quarantine as with the specific nature of the control measures that should be applied.

SARS is not the first and is unlikely to be the last emerging zoonotic infection of modern times. Much of the wider impact of SARS has been seen in the Far East, but in the West it has been Canada and in particular Ontario and the City of Toronto that has taken the brunt of the impact of this infection so far.

The circumstances leading to the initial case cluster are well reported and the reasons underlying the most recent and ongoing case cluster are also known..$^{5-7}$
It is important to see the current Canadian SARS outbreak in a wider context to appreciate the lessons it offers to others. Canada covers an extensive geographical area with a comparatively small but heavily urbanised population distribution. Of the present 33 million Canadians about 13 million live in Ontario, 9 million in the Greater Toronto area, and 3 million live in the City of Toronto itself. Within Toronto about 100000 people are Chinese or of Chinese descent. An understanding and appreciation of the demographics of populations can give the first clues as to the probable impacts of newly emerging infections and other urbanised areas with similar ethnic and social profiles to Toronto could be similarly affected in time. Opportunities can therefore be taken to target public information campaigns to population groups who are at increased risk. These include travellers to affected areas where transmission has been demonstrated and to local communities that have links with affected areas.

Sick or worried people will often present themselves to their local accident and emergency units and the key issue of whether or not local hospitals can promptly detect and isolate suspected cases is perhaps worthy of particular scrutiny.

Awareness among heathcare professionals is also important and although specific guidance needs to be given, as important is to provide support and reassurance for front line workers who are not immune to the same understandable concerns surrounding the emergence of an new infections as members of the public. Perhaps healthcare professionals need to be communicated as people first and professionals second?

We also need to be mindful of the lessons learned from communicating about other serious infections such as HIV. The assimilation of this information does not happen overnight and can be very difficult to come to terms with in the midst of an outbreak. Communication strategies should aim to pave the way now to minimise possible problems in the future by key messages early so that people have the time and opportunity to digest and accept them.

Control of infection in hospital and surveillance for infection will never be quite the same again. Focused infection control measures and public health intentions will need to be put in place using a risk assessment approach. The hazard analysis critical control point (HACCP) approach is one well known risk assessment model widely used in industry and in food hygiene and now increasingly being used and applied to infectious diseases and public health issues. ${ }^{89}$ This approach has the potential to provide a useful checklist for action to guide decision makers and public health professionals, as they become "task saturated" with a multitude of diverse problems in the heat of a major communicable disease incident. Pressure points in the health and social care system can be anticipated using a HACCP approach and some early measures put in place in advance. HACCP principles are currently being applied to the development of national contingency plans for SARS by the Health Protection Agency and critical control points defined for each phase of an evolving outbreak.

Prompt detection and appropriate isolation of hospitalised cases is one critical control point and suggests that in the future that there should be more investment in syndromic surveillance. Perhaps travel associated pneumonias and nosocomial pneumonias should be early candidates for such surveillance in the postSARS period. Most importantly we should look to constructively learn from the practical experience that others have gained from engaging to control SARS. Capturing, remembering, and learning from these experiences will enable the wider international community to be better prepared for not only SARS, but also for the next emerging infection that we will undoubtedly have to face in the future.

\section{$J$ Epidemiol Community Health} 2003;57:642-643

\section{Author's affiliations}

M Regan, Health Protection Agency (North West), UK

Correspondence to: Dr M Regan, CDSC-North West, Vernon Pritchard Court, 57a Upper Northgate Street, Chester, UK; mregan@phls.org.uk

\section{REFERENCES}

1 Anon. SARS in the city Canada Globe and Mail Friday 25th Apr 2003;A21.

2 Editorial. Where are the leaders when they're needed? Canada Globe and Mail Friday 25th Apr;A20

3 Leblanc D. Martin says PM is adrift. Canada Globe and Mail Friday 28th Apr;A1. 
4 WHO. Severe acute respiratory syndrome (SARS): status of the outbreak and lessons for the immediate future. http://www.who.int/ $\mathrm{csr} / \mathrm{media} / \mathrm{sars}$ wha.pdf

5 Poutanen SM, Lowe BE, Henry B, et al. Identification of SARS in Canada. N Engl J Med 2003;348: 1995-2003.
6 Booth CM, Larissa M, Matukas GA, et al. Clinical features and short term outcomes of 144 patients with SARS in the Greater Toronto Area. JAMA 2003;289:1-9.

7 Canada Communicable Disease Report. Update: Severe acute respiratory syndrome; Toronto, 2003. http://www.hc-sc.gc.ca/ pphb-dgspsp/publicat/ccdr-rmtc/03vol29/ prev/dr-sars0613.html.

8 MacDonald B, Engel D. A guide to HACCP for small businesses. Doncaster: Highfield Publications, 1996

9 Public Health Policy Unit. Scottish infection manual. Edinburgh: Scottish Office,

Department of Health, 1998:92.

\section{Severe acute respiratory syndrome}

\section{G Rezza}

\section{A challenge for public health}

n this issue of the journal, Lee and Abdullah focus on the adoption of hygienic and health promotion measures in Hong Kong for controlling the spread of severe acute respiratory syndrome (SARS). ${ }^{1}$ One of the interesting aspects of this work is that it provides an insider's point of view, yet these hygienic measures need to be discussed in the overall context of the outbreak, including the other public health interventions that have been performed in both Hong Kong and other heavily affected cities.

It should first be mentioned that one of the distinguishing characteristics of SARS is that for the first time in many years the entire world has perceived an outbreak as a life threatening event with a great non-discriminatory potential for diffusion, whereas this has not been the case for other epidemics of emerging infections in the era of antibiotics. For example, despite the fact that the outbreaks of Ebola and Lassa fever produced high case fatality rates in Sub-Saharan Africa, they remained for the most part confined to remote areas and were thus never truly perceived as global level threats by persons living in industrialised countries. Although the HIV/AIDS pandemic represents a true global level disaster, knowledge of the selective modalities of transmission has led to its being often perceived as affecting only marginalised people in wealthy countries and people living in poor resource countries.

The global level concern surrounding SARS began to take form when reports from Hong Kong and China's Guandong province incited the WHO to launch a global alert, unprecedented in its history, that recommended the postponement of all but essential travel to the affected areas and the screening of airline passengers ${ }^{2}$; around the same time, the public health measures for reducing the risk of transmission in the affected areas became extremely strict. None the less, it is fair to say that we were not prepared to cope with the SARS emergency, for several reasons. Specifically, SARS, which is caused by a new human coronavirus (referred to as "SARSCoV"), is mainly transmitted through respiratory secretions, and these types of infections are not as easily controlled as those transmitted through, for example, sexual intercourse or blood. Secondly, that the infection is viral makes treatment difficult, given the scarcity of effective antiviral drugs in general. Thirdly, there is not much experience with vaccines against other known human coronaviruses (229E and OC43-like), as they have only been associated with mild pathogens, which cause about 30\% of seasonal common colds.

However, despite these hurdles, the epidemic curves of SARS in Guandong, Hong Kong, Singapore, Beijing, Toronto, and Taiwan all showed a rather rapid decline after the implementation of stringent public health measures, ${ }^{3}$ and in Hanoi, where WHO officer Carlo Urbani recommended that stringent measures be adopted immediately after he identified the disease, the outbreak was contained within a few weeks. The group of Roy Anderson of Imperial College in London has emphasised that the spread of infection has been successfully limited because mixing and travel were restricted through measures that the authors defined as "draconian", including: the isolation of cases, contact tracing and mandatory home quarantine, suspension of school sessions, health declarations for visitors, isolation of residents of a building and their subsequent move to rural isolation camps, and body temperature checks for air passengers. ${ }^{4}$ Although the application and enforcement of these measures varied across the different affected areas, it can be safely be said that they were effective.
Insight into the reasons for this success has been provided by the dynamic mathematical models designed to determine how and why the disease had spread among populations in Asia and elsewhere. According to preliminary analyses of the outbreak in Hong Kong, SARS-CoV is more likely to be transmitted by direct contact or by larger virus laden droplets, which travel only one or two metres, as compared with lighter airborne particles or aerosols, as is the case for influenza and measles. ${ }^{56}$ This theory is supported by the comparatively low basic case reproduction number $\left(\mathrm{R}_{0}\right)$ (that is, the average number of persons infected by each case at the beginning of the epidemic), which seems to range from 2 to 4, with the exception of two super-spread events; the theory is also supported by the occurrence of clusters of cases linked to symptomatic people in a particular spatial setting (for example, healthcare facilities or households).

This success, which to some extent was unexpected, has played down the criticism concerning the supposed noneffectiveness of the cordone sanitaire in the era of globalisation. However, whether or not imposing these measures represents an unacceptable infringement of individual rights continues to be a matter of debate.

J Epidemiol Community Health 2003;57:643

\section{Author's affiliations}

G Rezza, Istituto Superiore di Sanità, Rome, Italy

Correspondence to: Dr G Rezza; g.rezza@iss.it

\section{REFERENCES}

1 Lee A, Abdullah ASM. Severe acute respiratory syndrome: a challenge for public health practice in Hong Kong. J Epidemiol Community Health 2003;57:655-8.

2 WHO. Wkly Epidemiol Rec 2003;78:97-120.

3 WHO. Cumulative number of reported probable cases. www.WHO.int/csr/sars/ country/2003_06_17/en/ laccessed 18 May 2003).

4 Donnelly CA, Grani AC, Leung GM, et al Epidemiological determinants of spread of causal agent of severe acute respiratory syndrome in Hong Kong. Lancet 2003;361 1761-6.

5 Riley S, Fraser C, Donnelly CA, et al. Transmission dynamics of the etiological agent of SARS in Homg Kong: impact of public health interventions. Science 2003:300:1961-6.

6 Lipsitch M, Cohen T, Cooper B, et al. Transmission dynamics and control of severe acute respiratory syndrome. Science 2003;300: 1966-70. 